\title{
Obstructive Sleep Apnea- Surgical Dilemmas
}

\author{
Novak Vukoje ${ }^{1 *}$ and Jon Garito ${ }^{2}$ \\ ${ }^{1}$ Otorhinolaryngology, Petrovaradin, Serbia \\ ${ }^{2}$ The inovator of new BAERF electrodes, USA
}

Submission: October 24, 2018; Published: October 30, 2018

*Corresponding author: Novak Vukoje, Otorhinolaryngology, Petrovaradin, Serbia

\section{Opinion}

If ever a disease is called fascinating, it will be a sleep of apnea. It implies a periodic stopping of breathing during sleep due to obstruction of the upper respiratory tract. Pathways lasting longer than 10 seconds and occurring more often than five times during one hour of sleep are a pathway of the diagnosis. The obstruction of obstructive apnea in the general population ranges from $5-7 \%$. Four times is more common in males and seven times in people with BMI over $35 \mathrm{~kg} / \mathrm{m} 2$. The apnea frequency in the children's population is about $2.5 \%$. Typically, people with sleep apnea sleep. Sleepiness and apnea are two extremities of the same disease. According to AHI / Apnea-Hypopnea index / and percentage of blood saturated oxygen is divided into:
a) Light AHI 5-15 (Sa02 saturated $>85 \%)$
b) Mild AHI $15-30$ (Sa02 of $80-85 \%)$
c) Severe $\mathrm{AHI}>30(\mathrm{SaO} 2$ saturated $<80 \%)$



Figure 1: Local finding in the throat- noisy sleep and breaks in breathing.

There is obstructive, mixed and central apnea. The question is why OSA only occurs during sleep and is the cause of the instability of the airway in transition from waking through NonRem to Rem Sleep? Clinical examination usually reveals the cause of snoring and apnea in children. Hypertrophic tonsils and enlarged third extremities are the most common cause of snoring and respiration in this population (Figure 1). The disease gradually occupies epidemiological conditions with significant comorbidity. An obstructive sleep apnea represents a wide range of clinical symptoms. Statistics show that over $30 \%$ of untreated patients begin to develop complications in the next couple of years. The frequency of cardiovascular and cerebrovascular diseases, elevated blood pressure, diabetes, in children with urinary nightmares in bed, etc., is more common in apneic patients than in healthy people. Life expectancy in these patients is shorter by 5-10 years, and it is also described sudden death during sleep.

Apnea belongs to the group of "silent killers" It occurs in deep sleep phases and in the stage of REM sleep. It can also be present in people with normal body weight and a regular physical finding. What characterizes the apnea and what they complain about is:

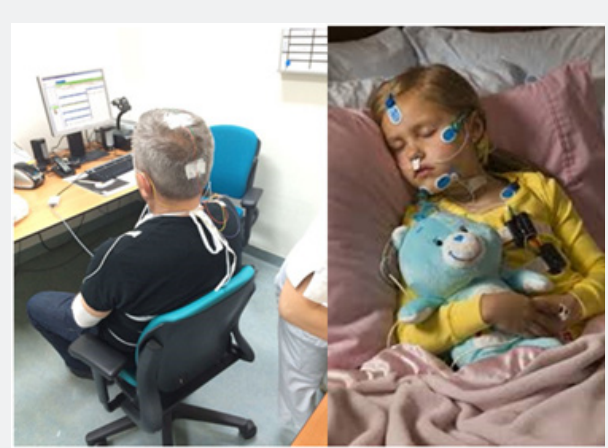

Figure 2: Patient is prepared for polysomnographic examination.

a) Intermittable noisy sleep with periods of silence longer than ten seconds

b) Turned daily drowsiness

c) Chronic fatigue

d) Excessive night sweats, especially in the head and neck area

e) Display motor activity during sleep

f) Morning headaches 
Determining the degree of daily alertness can be evaluated by Epfort's drowsiness scale. In order to diagnose this syndrome, in addition to anamnesis, clinical examination, fiberoptic nasopharyngoscopy, etc. Polysomnography is used as a gold standard (Figure 2). After the diagnosis, a decision is made about the treatment. The patient is usually obese, if he is weight reduction is recommended, sleep hygiene, avoiding evening meals, smoking, sedatives, etc. From the therapy, devices and devices against snoring and apnea, especially dentures that move the lower fork to progress, application of CPAP apparatus or surgery (Figure 3). CPAP should be the first line of medical treatment for mild and severe apnea. It represents safe, effective and safe therapy in the treatment of these patients (opinion is a specialist in sleep medicine). A person is considered to be suitable for the CPAP apparatus if it is used for $4 \mathrm{~h}$ during the night, five days a week.

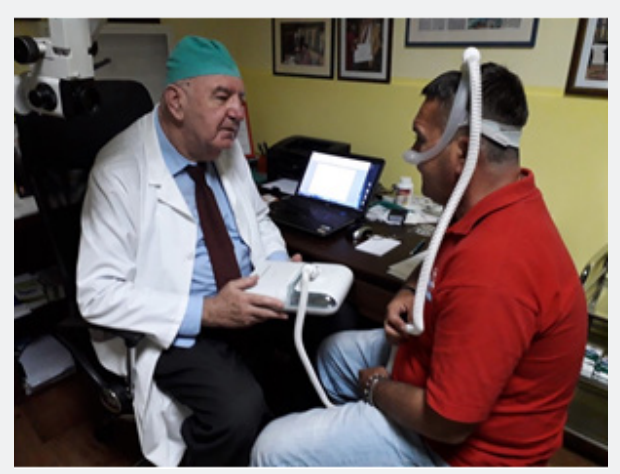

Figure 3: The patient is attached to the CPAP apparatus.

Unfortunately, the reality is that about $30 \%$ of persons with apnea do not tolerate the device and in those cases, it represents an inadequate level of treatment with potentially dangerous consequences. Moreover, a certain number of these patients have some abnormalities of the upper airway that make it difficult to apply CPAP and require surgical treatment (advocates for operative treatment). CPAP works on the principle of positive air pressure (while the lungs work on the principle of negative). It serves for prevention, not for the treatment of apnea (while the effect is used, when it stops - the state returns to the previous one). It cannot be used in the stage of inflammation of the upper respiratory tract. During its application, the following subjective symptoms may occur:

i. feeling suffocated

ii. Claustrophobia

iii. Difficult expiration

\section{Obstructive Sleep Apnea- Surgical Dilemmas}

If ever a disease is called fascinating, it will be a sleep of apnea. It implies a periodic stopping of breathing during sleep due to obstruction of the upper respiratory tract. Pathways lasting longer than 10 seconds and occurring more often than five times during one hour of sleep are a pathway of the diagnosis. The obstruction of obstructive apnea in the general population ranges from $5-7 \%$. Four times is more common in males and seven times in people with BMI over $35 \mathrm{~kg} / \mathrm{m} 2$. The apnea frequency in the children's population is about $2.5 \%$. Typically, people with sleep apnea sleep. Sleepiness and apnea are two extremities of the same disease. According to AHI / Apnea-Hypopnea index / and percentage of blood saturated oxygen is divided into:

\section{a. Light AHI 5-15 (Sa02 saturated $>85 \%)$ \\ b. Mild AHI 15-30 (Sa02 of 80-85\%) \\ c. Severe $\mathrm{AHI}>30$ (SaO2 saturated $<80 \%)$}

There is obstructive, mixed and central apnea. The question is why OSA only occurs during sleep and is the cause of the instability of the airway in transition from waking through Non-Rem to Rem Sleep? Clinical examination usually reveals the cause of snoring and apnea in children. Hypertrophic tonsils and enlarged third extremities are the most common cause of snoring and respiration in this population. The disease gradually occupies epidemiological conditions with significant comorbidity. An obstructive sleep apnea represents a wide range of clinical symptoms. Statistics show that over $30 \%$ of untreated patients begin to develop complications in the next couple of years. The frequency of cardiovascular and cerebrovascular diseases, elevated blood pressure, diabetes, in children with urinary nightmares in bed, etc., is more common in apneic patients than in healthy people. Life expectancy in these patients is shorter by 5-10 years, and it is also described sudden death during sleep. Apnea belongs to the group of "silent killers" It occurs in deep sleep phases and in the stage of REM sleep. It can also be present in people with normal body weight and a regular physical finding. What characterizes the apnea and what they complain about is:

a) Intermittable noisy sleep with periods of silence longer than ten seconds

b) Turned daily drowsiness

c) Chronic fatigue

d) Excessive night sweats, especially in the head and neck area

e) Display motor activity during sleep

f) Morning headaches

Determining the degree of daily alertness can be evaluated by Epfort's drowsiness scale. In order to diagnose this syndrome, in addition to anamnesis, clinical examination, fiberoptic nasopharyngoscopy, etc. Polysomnography is used as a gold standard. After the diagnosis, a decision is made about the treatment. The patient is usually obese, if he is weight reduction is recommended, sleep hygiene, avoiding evening meals, smoking, sedatives, etc. From the therapy, devices and devices against snoring and apnea, especially dentures that 


\section{Global Journal of Otolaryngology}

move the lower fork to progress, application of CPAP apparatus or surgery. CPAP should be the first line of medical treatment for mild and severe apnea. It represents safe, effective and safe therapy in the treatment of these patients (opinion is a specialist in sleep medicine). A person is considered to be suitable for the CPAP apparatus if it is used for $4 \mathrm{~h}$ during the night, five days a week. Unfortunately, the reality is that about $30 \%$ of persons with apnea do not tolerate the device and in those cases it represents an inadequate level of treatment with potentially dangerous consequences. Moreover, a certain number of these patients have some abnormalities of the upper airway that make it difficult to apply CPAP and require surgical treatment (advocates for operative treatment).

CPAP works on the principle of positive air pressure (while the lungs work on the principle of negative). It serves for prevention, not for the treatment of apnea (while the effect is used, when it stops - the state returns to the previous one). It cannot be used in the stage of inflammation of the upper respiratory tract.

During its application, the following subjective symptoms may occur:
a) Feeling suffocated
b) Claustrophobia
c) Difficult expiration

d) Discomfort while sleeping

e) Aerofagia

Positive pressure over the mask can cause:

a) Nasal congestion

b) Epistaxis

c) Dry mouth

d) Conjunctivitis and other (Figure 4)

Multiple advantages exist with radiowave surgery when compared with other surgical techniques - the most significant being simultaneous cutting and coagulation without significant lateral tissue damage, therefore lessening postsurgical pain and ensuring much faster healing. Another advantage is pressureless incision that can be performed with ease even in the depth and in difficult areas. The electrodes are reusable and may be kept in cold sterilization solution when not in use. Use of radiofrequency in performance of various surgeries results in less trauma to the cells, less fibrous scarring and less postoperative discomfort, compared to laser and electrocautery surgery. Depending on the part of the world, culture, religion, civilization, and others, according to the snoring surgery, it has changed from a very conservative to rather aggressive. The choice of surgery is not always simple because of the existence of arguments for and against each method. Much more important is whether surgery really the right option for your treatment.

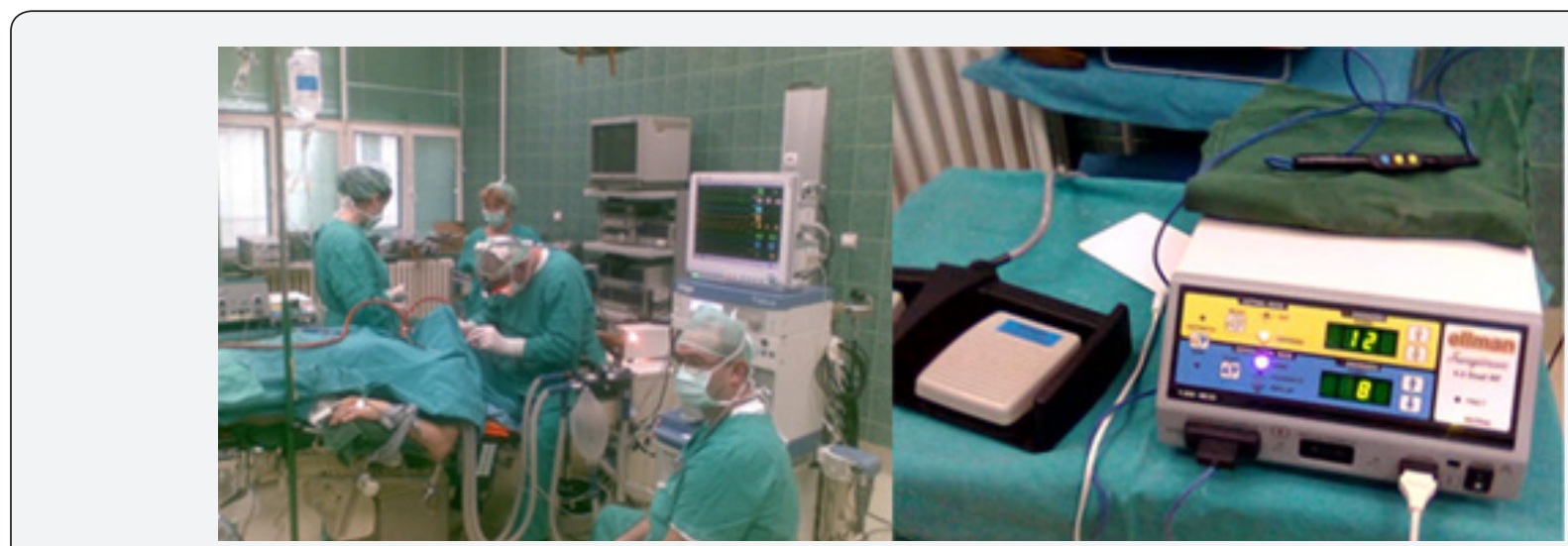

Figure 4: Surgical Orl Team on The Task. Obstructions are a pato-anatomical problem of the surgical domain / surgeon opinion /We use Ellman Sugitron with the new BAE RF electrodes that is new challenges in Radiovawe Surgery. The inovation of this electrods is dr Jon Garito from USA.

Not all patients are treated in one treatment, and there is no one treatment for everyone. It is a fantasy that all patients can be surgically cured, and that surgery is $100 \%$ effective for all those who are undergoing surgery. There is a whole range of operating procedures that are determined by the site of obstruction (endonasal surgery, palatopharyngeal region surgery, glossopharyngolaryngeal region surgery, maxillarymandibular surgery, operations to remove fat tissue from the cervical region, tracheotomy, combined operations, etc.). What is necessary before every surgical procedure- a) Precise marking of the site and degree of obstruction

b) Adequate surgical procedure

c) If there are more obstructions at different levels, first expand the largest one.

d) If it does not succeed, extend the other sites of obstruction and leave them sufficiently and permanently open all night long-every night (Figure 5).

Poor operative treatment results are most commonly due to: 


\section{Global Journal of Otolaryngology}

a) Incorrect site obstruction detection

b) Poor surgery (insufficient extension of the obstruction site)

c) Postoperative appearance of obstruction at the second level

d) Weight gain

e) Probability of snoring

f) Changing the habit of life

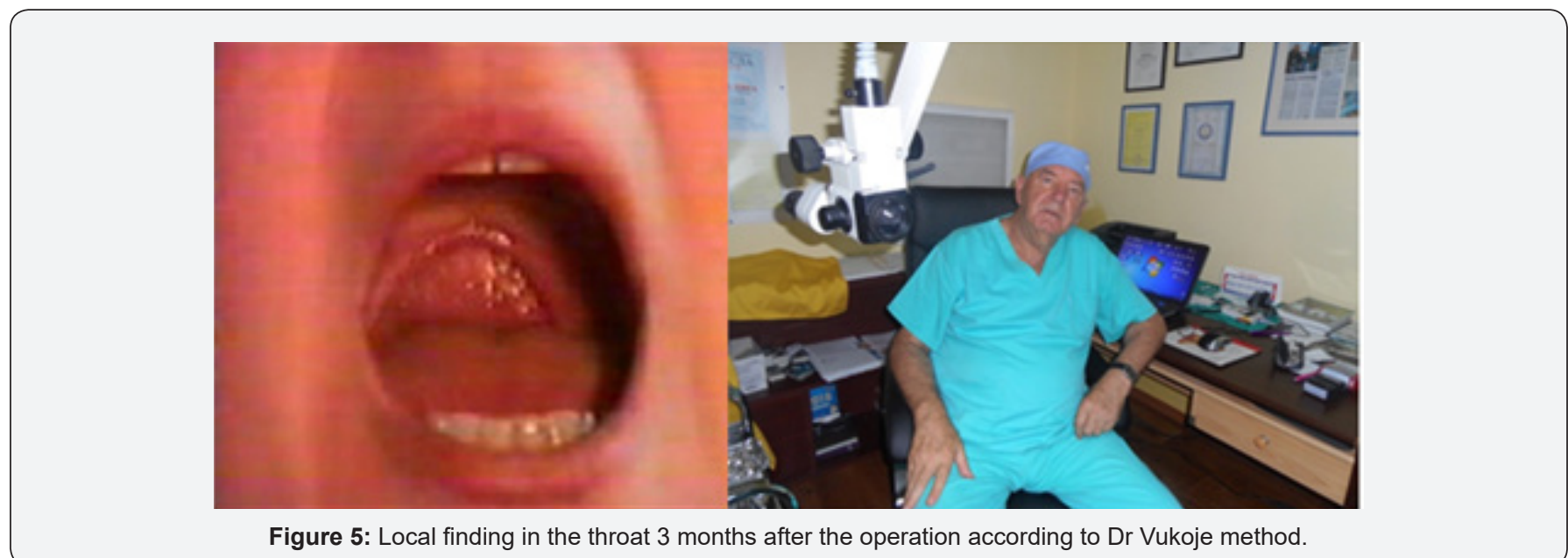

\section{Conclusion}
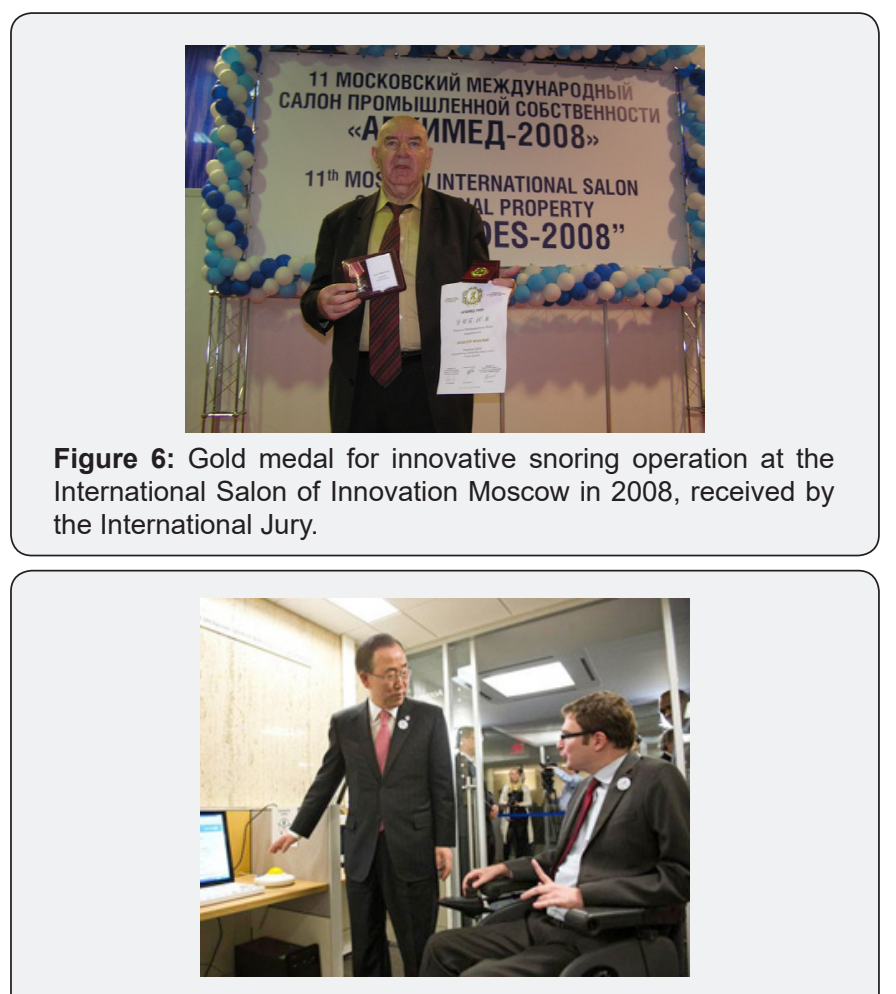

Figure 7: President of the World Association of Handicapped Persons from New York found rescue in Serbia.

Surgery is considered successful if postoperative parameters compared to preoperative improved by more than 50\%/
RDI, AHI/ with increasing oxygen saturation over 90\% and elimination of intense daily drowsiness. Clinical classification by Friedman and Mallampati is a fairly reliable indicator of the success of surgery: the higher the stage of apnea surgical success is weaker. The lower the level of obstruction, surgery is more difficult, and success is worse, and they should consider the use of CPAP. The decision on what is first and what the last choice of treatment of these patients should be made after a detailed diagnostic treatment with a consultative collaboration with specialists dealing with this issue. Additional research will define the role of all parameters that can be individually or jointly served as predictors of the success of surgery in OSA patients, because medicine requires a method that will be a success and not a failure. The medicine's success does not consist in how many patients we prescribed CPAPs in how far we have freed them from the mentioned device (Figures 6,7). You have suffered from a "sleep apnea" that, unlike American doctors, Dr. Novak Vukoje successfully solved. How do you comment on the fact that in Serbia you managed to solve this problem, and that you could not in America? A completely different approach to medicine. I was prescribed a breathing apparatus called CPAP. I had trouble with it. Dr Vukoje, with two interventions, one in my nose and one on the palate, completely freed my airways and solved my problem. It's been four years now since my operation and I am really very grateful to Dr. Vukoje. I do not use the device at all, I sleep peacefully. 
This work is licensed under Creative Commons Attribution 4.0 License

(c) (1) DOI: 10.19080/GJO.2018.18.555976
Your next submission with Juniper Publishers will reach you the below assets

- Quality Editorial service

- Swift Peer Review

- Reprints availability

- E-prints Service

- Manuscript Podcast for convenient understanding

- Global attainment for your research

- Manuscript accessibility in different formats

(Pdf, E-pub, Full Text, Audio)

- Unceasing customer service

Track the below URL for one-step submission https://juniperpublishers.com/online-submission.php 